\title{
The Effects of Socio-cultural Factors on Medical College Students' Self-Rated Health Status and Health-Promoting Lifestyles in Eritrea: A Cross-sectional Study
}

\author{
Isayas Afewerki Abraham 1, *, Zewdi Amanuel Dagnew², Eyasu Habte Tesfamariam³, \\ Ghirmay Ghebreigziabher Beraki ${ }^{2}$, Oliver Okoth Achila ${ }^{4}$, Yemane Fessehaye Berhe ${ }^{2}$, \\ Yingchun Dai ${ }^{5}$ \\ ${ }^{1}$ Department of Community Medicine and Primary Health Care, Orotta College of Medicine and Health Sciences, Asmara, Eritrea \\ ${ }^{2}$ Department of Nursing, Orotta College of Medicine and Health Sciences, Asmara, Eritrea \\ ${ }^{3}$ Department of Statistics, Eritrean Institute of Technology, Mai-Nefhi, Eritrea \\ ${ }^{4}$ Department of Allied Health, Orotta College of Medicine and Health Sciences, Asmara, Eritrea \\ ${ }^{5}$ Department of Epidemiology, School of Public Health, Southern Medical University, Guangzhou, China \\ Email address: \\ isayasafewerki2050@gmail.com (I. A. Abraham), zewdiamanuel2050@gmail.com (Z. A. Dagnew), \\ yohoshua79@yahoo.com (E. H. Tesfamariam), gberaki83@gmail.com (G. G. Beraki), oliverachila@gmail.com (O. O. Achila), \\ yemane_fish@yahoo.com (Y. F. Berhe), yingchun78@hotmail.com (Yingchun Dai) \\ ${ }^{*}$ Corresponding author
}

\section{To cite this article:}

Isayas Afewerki Abraham, Zewdi Amanuel Dagnew, Eyasu Habte Tesfamariam, Ghirmay Ghebreigziabher Beraki, Oliver Okoth Achila, Yemane Fessehaye Berhe, Yingchun Dai. The Effects of Socio-cultural Factors on Medical College Students' Self-Rated Health Status and Health-Promoting Lifestyles in Eritrea: A Cross-sectional Study. Journal of Health and Environmental Research.

Vol. 7, No. 1, 2021, pp. 30-38. doi: 10.11648/j.jher.20210701.17

Received: January 20, 2021; Accepted: January 28, 2021; Published: March 4, 2021

\begin{abstract}
Sub-optimal health status (SHS) and unhealthy lifestyle among college students have become a major focus for research on public health worldwide. Hence, this study was designed to assess the effects of socio-cultural factors on medical college students' self-rated health status (SRH) and health-promoting lifestyles (HPL) in Eritrea. A descriptive cross-sectional study was conducted at Orotta School of Medicine (OSM), using a self-administered questionnaire. Data was collected from all medical students who had fulfilled the inclusion criteria using Sub-Optimal Health Measurement Scale (SHMS V1.0) and Health-Promoting Lifestyle Profile-II (HPLP-II) scale questionnaires. Independent samples t-test, ANOVA, Chi-square test, Pearson's correlation coefficient and Binary multivariate logistic regression were performed. Data analysis was undertaken using SPSS version 22. The overall SRH was significantly higher among college students with BMI of 25 to $29.9(\mathrm{M}=88.23, \mathrm{SD}=6.28)$ as compared to $<18.5(p=0.027)$ and 18.5 to $24.9(p=0.027)$. Moreover, physiological subscale of SRH was significantly related to gender $\left(\mathrm{M}_{\text {males }}=88.96 \mathrm{Vs} \mathrm{M}_{\text {females }}=85.41\right.$, $p=0.001)$ and monthly stipend $\left(\mathrm{M}_{\text {income }}=89.52 \mathrm{Vs} \mathrm{M}_{\text {no-income }}=87.28, p=0.040\right)$. On the other hand, physical activity of HPL was found to vary by gender $\left(\mathrm{M}_{\text {males }}=2.12 \mathrm{Vs} \mathrm{M}_{\text {females }}=1.87, p=0.005\right)$ and alcohol consumption ( $\left.\mathrm{M}_{\text {drinkers }}=2.22 \mathrm{Vs} \mathrm{M}_{\text {non-drinkers }}=1.99, p=0.016\right)$. Nutrition differences of HPL were observed in BMI of 25 to 29.9 ( $\mathrm{M}=2.40, p=0.028)$, internship students $(\mathrm{M}=2.15, p=0.027)$, and monthly income $(\mathrm{M}=2.11, p=0.029)$. The overall $\mathrm{SRH}$ was significantly correlated with the overall HPL $(\mathrm{r}=0.493, p<0.001)$. In addition, students who had high ( $\geq$ good) HPL were more likely to rate themselves as healthier: AOR=4.97, 95\% CI: $1.28-19.32$ and $\mathrm{AOR}=3.73,95 \% \mathrm{CI}: 1.09-12.80$. In all, the study adds to the evidence on the impact of socio-cultural influences' on SRH (gender, BMI, stipend) and HPL (gender, alcohol, BMI, study year, stipend) of medical students.
\end{abstract}

Keywords: Socio-cultural Factors, Self-rated Health Status, Health-promoting Lifestyle, Medical Students, Eritrea 


\section{Introduction}

Currently, lifestyle is one of the most essential factors affecting an individual's health status and has a great role in prevention of chronic diseases [1-5]. Healthy lifestyle refers to individual's capacity to control his/her behaviors that affect health and plan his/her daily activities by choosing behaviors that are appropriate for health [6-8], whereas poor lifestyle is defined as going bed late, work and study related stress, physical inactivity and poor diet pattern [3]. On the other hand, health-promoting lifestyle (HPL) comprises a multidimensional pattern of self-initiated perceptions (beliefs) and activities (actions) aimed at prevention of disease and/or maintenance and improvement of wellness [3, 6, 9]. Self-rated health status (SRH), a single survey questionnaire developed by WHO, is a subjective reflection of health status called "perceived" or "subjective" health $[10,11]$.

Although healthy lifestyle behaviors are important for individuals in all periods of life, these are of primary importance during youth [6]. Adoption of unhealthy lifestyle behaviors can easily occur at this stage making college students a predominantly susceptible group [12]. Students are in a dynamic and transition period of growth and development. This period shows rapid changes in the student's body, mind and social interaction patterns. Thus, at this stage, students are usually exposed to a new, challenging and competitive environment. Most of them are facing and experiencing independence, behavioral changes, new friendships, financial pressures, stress, insufficient nutritional intake, lack of physical activity, poor time management and starting responsibility in their lives $[4,7,12,13]$.

The WHO stated that $60 \%$ of individual's quality of life and health rests on their behavior and lifestyle [13, 14]. According to some studies, $53 \%$ of deaths attributable to chronic diseases are related to lifestyle $[1,5]$. Moreover, unhealthy lifestyle behavior adopted during youth can have a life-long impact on an individual and, by extension, the entire population $[5,13]$. Over the past thirty, year, chronic diseases have increased at an alarming rate [6]. Many studies clearly showed that premature morbidity/disease and mortality/death are primarily due to unhealthy lifestyles and behaviors [12]. Africa, with a large number of youth, is in a transitional era from communicable to non-communicable diseases, however, there are limited number of related studies focused on college students' SRH and HPL.

Sub-optimal health status (SHS) and unhealthy lifestyle among college students have become major public health concerns and a research focus worldwide [6, 13, 15]. In particular, researchers in Sub Saharan Africa (SSA), and by extension Low- and medium-income countries (LMIC); have paid little attention to cultural influences (contemporary or otherwise) on SRH and HPL among students $[6,16]$. Indeed, multiple studies, conducted exclusively in high-income countries (HIC), have demonstrated that economic and demographic drivers of unhealthy behavior in specific groups of young people are mitigatable if identified and treated at an early stage $[2,6]$. However, the severe lack of contextspecific SRL and HPL data limit the ability for the creation of public health strategies for prevention of unhealthy behavior among the youth in the region.

In this study, the focus was on medical students. During their studies, medical students obtain better health knowledge than other students or the general population. That knowledge does not, however, directly transfer to the students' own preventive behavior [16]. In Eritrea, there is only one medical school which is located in the capital city, Asmara. The students are from diverse areas of the country and may therefore face challenges/or difficulties adjusting to the disparate cultural milieu in the more cosmopolitan Asmara city. This may have a lasting impact on their lifestyles and behaviors. The ultimate purpose of the study was, therefore, to explore and examine how socio-cultural factors influence Eritrean medical college students' SRH and HPL, and also to assess the relationship between SRH and HPL among medical college students. Importantly, we tried to evaluate whether the patterns of sociocultural drivers observed in this setting are comparably to patterns observed in high income countries (HIC) where similar studies have been undertaken. This information can then be leveraged to design context-specific measures directed at promoting and motivating healthy lifestyle in a subset of students in the region.

\section{Methods}

\subsection{Study Design and Period}

A descriptive cross-sectional study was carried out between August 9 and September 14, 2018. No sample size determination method was applied, because complete enumeration was performed.

\subsection{Study Population and Setting}

A total of 201 medical students, in their $2^{\text {nd }}, 3^{\text {rd }}, 4^{\text {th }}, 5^{\text {th }}$ and $6^{\text {th }}$ academic years, were invited to participate voluntarily and anonymously at the selected OSM. However, students who met the following inclusion criteria: medical students between $2^{\text {nd }}$ and $6^{\text {th }}$ year of study, who stayed in the college for more than six months, and had not been diagnosed with critical illness in the previous 4 weeks were 192.

\subsection{Data Collection Tool and Techniques}

The three main components of the data collection tool used in the survey were socio-demographic characteristics, suboptimal health measurement scale version 1.0 (SHMS V1.0), and health promoting life style II (HPLP-II) scale. Time to fill the questionnaires through self-administration ranged from 20 to 30 minutes.

\subsubsection{Socio-demographic Characteristics}

Self-administered questionnaire was disseminated to obtain data on participants socio-demographic information including; age, gender, level of education, smoking habits, alcohol consumption, financial status, length of stay in college, and body mass index (BMI) $\left(\mathrm{kg} / \mathrm{m}^{2}\right)$. 


\subsubsection{Self-rated Health Status (SRH)}

The second part was evaluation of SRH, which was performed according to the clinical guidelines for SRH published by the China association of Chinese medicine. To measure SRH, we used the Sub-Optimal Health Measurement Scale Version 1.0 (SHMS V1.0), which is a multidimensional and self-report symptom inventory [3]. SHMS V1.0 comprises 39 items with 3 dimensions: physiological health (14 items) includes physical condition (3 items), organ function (6 items), body movement function ( 3 items) and vigor ( 2 items); psychological health (12 items) comprises positive emotion (4 items), psychological symptoms (6 items) and cognitive function ( 2 items); and social health ( 9 items) contains social adjustment (4 items), social resources (3 items) and social support ( 2 items), and 4 other items for health status evaluation, in which participants were asked: "What is your general feeling in terms of physical/psychological/ social/general health?" The 35 items of five-point Likert-type (1=never, $2=$ occasionally, $3=$ sometimes, $4=$ often, $5=$ routinely) were used to measure the participants self-reported health problems $[5,6]$.

The original score of every factor was equivalent to the total score of items included in this factor, and the original score of every dimension was equivalent to the total score of factors included. Subsequently, the original raw score was converted to obtain the final score accordingly. Ultimately, the converted scores were used to analyze the outcomes-that is, the total scores for each SHMS V1.0 domains were transformed into a range of 0 (worst possible health status measured by the questionnaire) to 100 (best possible health status), with a highest score representing better SRH [2].

\subsubsection{Health-Promoting Lifestyle (HPL)}

The health-promoting lifestyle profile (HPLP) was initially developed by Walker, Sechrist, and Pender in 1987 and later revised as Health Promoting Lifestyle Profile-II (HPLP-II) in 1997 [9]. HPLP-II containing 52-items was used to evaluate the students' HPL. It consists of 6 dimensions namely: health responsibility (9 items), spiritual growth (9 items), physical activity ( 8 items), nutrition $(9$ items $)$, interpersonal relationships (9 items), and stress management ( 8 items). This measuring instrument can be used to assess the frequency of health-promoting behavior using a selfreporting. To determine the frequency of each behavior, a 4point Likert scale (1="never", $2=$ "sometimes", $3=$ "often", and 4="routinely") was used, in which all items of HPLP-II are affirmative, with no reverse questions $[5,6]$.

The score for overall HPL is obtained by calculating the mean of the individual's responses to all 52 items; six subscale scores are obtained similarly by calculating a mean of the responses to subscale items. The use of means rather than sums of scale items is recommended to retain the 1 to 4 metric of item responses and to allow meaningful comparisons of scores across subscales. Hence, the final total score was obtained by adding the scores for all the items and dividing by the total number of items $[5,6]$. To determine the levels of HPLP-II subscales, the scores were divided by quartiles into low (1.00-2.38), moderate (2.39-2.61), good
(2.62-2.91) and excellent (2.92-4.00). High scores indicated a greater frequency of health-promoting behaviors. A mean of 2.50 was considered to be a positive response, in line with previous specifications [6].

\subsection{Validity and Reliability}

We used a previously validated English version of SHMS V1.0 and HPLP-II questionnaires. The composite Cronbach's alphas for SRH (after converting the negatively worded items) and HPL were 0.819 and 0.874 respectively. Moreover, Cronbach's alphas for physiological health, psychological health, and social health were $0.657,0.669$, and 0.785 respectively. On the other hand, Cronbach's alphas for health responsibility, spiritual growth, physical activity, nutrition, interpersonal relationship, and stress management were 0.769 , $0.772,0.572,0.678,0.788$, and 0.629 respectively.

\subsection{Pre-test}

A pre-test was conducted on 20 students at Asmara College of Health Sciences in August 2018, to evaluate the clarity, applicability and understandability of the tools, to estimate the time needed to complete the questionnaire, and to get comments with regard to the number of questions. The questionnaire was distributed by data collectors who were fluent in English. The pre-designed questions which were unclear or ambiguous were subsequently simplified by the investigators. Finally, necessary modifications were undertaken after the pre-test.

\subsection{Data Analysis}

SPSS version 22 was the statistical program used to analyze the data. Descriptive analyses for the demographic data was done using frequency (percent), and median (IQR). Tables were used to provide an overall and comprehensible presentation and description of data. The internal consistency of both SRH and HPL at subscale level and composite were assessed using Cronbach's alphas. An independent samples ttest, ANOVA, Chi-square/Fishers exact test for independence were used to compare mean differences and proportions between the groups, as appropriate. Bonferroni post-hoc test was also performed for variables that were found to be significant in ANOVA. The correlation of SRH/HPL with socio-cultural factors was tested using Pearson's coefficient correlation. Binary multivariate logistic regression was used to explore the association between categories of SRH and HPL among medical college students. A $p$ value of less than or equal to 0.05 was considered as statistically significant.

\section{Results}

\subsection{Socio-demographic Characteristics}

A total of 201 questionnaires were distributed during the study period, and 198 completed responses were received (response rate of $98.5 \%$ ). Nine participants did not meet the inclusion criteria (Six participants were diagnosed with chronic 
illness and three participants did not complete the questionnaire). Therefore, a total of 192 participants were included in this study. The median age of the 192 students in the research study was 23.5 years $(\mathrm{IQR}=4)$. Out of the total participants, $70.3 \%$ were males and the majority of students (98.4\%) were single, and only $28.1 \%$ had monthly income. Most of the participants were Christian (91.1\%) and belonged to the Tigrigna ethnic group $(92.7 \%)$. Of the students, $1 \%$ was smokers and $22.4 \%$ were habitual alcohol users. Besides, minimum and maximum BMI was 14.5 and 27.2, respectively, with a median of $19.4 \mathrm{~kg} / \mathrm{m}^{2}(\mathrm{IQR}=3.7)$ (Table 1$)$.

Table 1. Characteristics of the participants.

\begin{tabular}{|c|c|c|c|}
\hline Characteristics & & Frequency & Percent \\
\hline \multicolumn{4}{|c|}{ Age $($ Min. $=19$, Max. $=36$, Median=23.5, IQR=4) } \\
\hline & Less or equal 25 & 147 & 76.6 \\
\hline & Greater than 25 & 45 & 23.4 \\
\hline \multicolumn{4}{|l|}{ Gender } \\
\hline & Male & 135 & 70.3 \\
\hline & Female & 57 & 29.7 \\
\hline \multicolumn{4}{|c|}{ BMI $($ Min. $=14.5$, Max. $=27.2$, Median=19.4, IQR=3.7) } \\
\hline & Less than 18.5 & 65 & 33.9 \\
\hline & 18.5 to 24.9 & 122 & 63.5 \\
\hline & 25.0 to 29.9 & 5 & 2.6 \\
\hline \multicolumn{4}{|l|}{ Ethnicity } \\
\hline & Tigrigna & 178 & 92.7 \\
\hline & Others* & 14 & 7.3 \\
\hline \multicolumn{4}{|l|}{ Religion } \\
\hline & Christian & 175 & 91.1 \\
\hline & Muslim & 12 & 6.3 \\
\hline & Others & 5 & 2.6 \\
\hline \multicolumn{4}{|l|}{ Marital Status } \\
\hline & Single & 189 & 98.4 \\
\hline & Married & 3 & 1.6 \\
\hline \multicolumn{4}{|l|}{ Study Year } \\
\hline & Second Year & 21 & 10.9 \\
\hline & Third Year & 25 & 13.0 \\
\hline & Fourth Year & 35 & 18.2 \\
\hline & Fifth Year & 72 & 37.5 \\
\hline & Internship & 39 & 20.3 \\
\hline \multicolumn{4}{|c|}{ Alcohol Consumption } \\
\hline & Consumers & 43 & 22.4 \\
\hline & Non-consumers & 149 & 77.6 \\
\hline \multicolumn{4}{|l|}{ Smoking Status } \\
\hline & Smokers & 2 & 1.0 \\
\hline & Non-smokers & 190 & 99.0 \\
\hline \multicolumn{4}{|l|}{ Monthly Stipend } \\
\hline & Yes & 54 & 28.1 \\
\hline & No & 138 & 71.9 \\
\hline \multicolumn{4}{|c|}{ Years of stay in the School } \\
\hline & 2 to 5 years & 71 & 37.0 \\
\hline & 6 to 10 years & 121 & 63.0 \\
\hline
\end{tabular}

Others*: Tigre $=11$, Bilen $=2$, Saho $=1$

\subsection{Level of SRH and Its Components Among the Students}

The average SRH level among the medical college students was 80.52 (95\% CI: 79.58, 81.46). Moreover, relatively higher level of physiological health $(\mathrm{M}=87.91$, 95\% CI: 86.94, 88.87) was observed among the students compared to psychological health $(\mathrm{M}=75.46,95 \% \mathrm{CI}$ : $74.26,76.66)$ and social health $(\mathrm{M}=75.58,95 \% \mathrm{CI}: 74.07$, 77.48) (Table 2).
Table 2. Level of SHMS V1.0 and its dimensions (out of 100) of college students.

\begin{tabular}{llll}
\hline Dimensions & $\begin{array}{l}\text { Minimum, } \\
\text { Maximum }\end{array}$ & Mean (SD) & 95\% CI \\
\hline Physiological Health & $67.14,100.00$ & $87.91(6.82)$ & $86.94,88.87$ \\
Psychological Health & $43.33,95.00$ & $75.46(8.41)$ & $74.26,76.66$ \\
Social Health & $37.78,97.78$ & $75.78(11.96)$ & $74.07,77.48$ \\
Overall SRH & $58.86,97.14$ & $80.52(6.62)$ & $79.58,81.46$ \\
\hline
\end{tabular}

\subsection{Level of HPL and Its Components Among the Students}

The overall mean score of HPL among the medical college students was 2.48 (95\% CI: 2.44, 2.52). Relatively, higher score of spiritual growth ( $\mathrm{M}=3.22,95 \% \mathrm{CI}$ : 3.16, 3.27), interpersonal relationship ( $\mathrm{M}=2.91, \mathrm{CI}: 2.84,2.98)$, and stress management $(\mathrm{M}=2.55$, 95\% CI: 2.48, 2.61) were observed among the students compared to other dimensions (Table 3).

Table 3. Level of HPLP-II and its dimensions (out of 4) of college students.

\begin{tabular}{llll}
\hline Dimensions & $\begin{array}{l}\text { Minimum, } \\
\text { Maximum }\end{array}$ & Mean (SD) & $\mathbf{9 5 \%}$ CI \\
\hline Health Responsibility & $1.11,3.56$ & $2.11(0.49)$ & $2.04,2.18$ \\
Spiritual Growth & $1.22,4.00$ & $3.22(0.39)$ & $3.16,3.27$ \\
Physical Activity & $1.00,3.38$ & $2.04(0.56)$ & $1.96,2.12$ \\
Nutrition & $1.11,3.33$ & $2.01(0.41)$ & $1.95,2.07$ \\
Interpersonal Relationship & $1.44,4.00$ & $2.91(0.49)$ & $2.84,2.98$ \\
Stress Management & $1.25,3.75$ & $2.55(0.46)$ & $2.48,2.61$ \\
Overall HPLP-II & $1.63,3.25$ & $2.48(0.30)$ & $2.44,2.52$ \\
\hline
\end{tabular}

Table 4. Comparison of the scores of SHMS V1.0 and its dimensions across categories of demographic characteristics.

\begin{tabular}{|c|c|c|c|c|}
\hline Characteristics & $\begin{array}{l}\text { Overall SRH, } \\
\text { M (SD) }\end{array}$ & $\begin{array}{l}\text { PHY, M } \\
\text { (SD) }\end{array}$ & PSY, M (SD) & $\begin{array}{l}\text { SOCL, M } \\
\text { (SD) }\end{array}$ \\
\hline \multicolumn{5}{|l|}{ Gender } \\
\hline Male & $80.90(6.85)$ & $88.96(6.80)$ & $75.21(8.73)$ & $75.93(12.35)$ \\
\hline Female & $79.63(6.01)$ & $85.41(6.23)$ & $76.05(7.65)$ & $75.40(11.07)$ \\
\hline p-Value & 0.203 & $0.001 * *$ & 0.527 & 0.778 \\
\hline \multicolumn{5}{|l|}{ Age } \\
\hline Less or equal 25 & $80.45(6.41)$ & $87.47(6.83)$ & $75.88(7.80)$ & 75.63 (11.67) \\
\hline Greater than 25 & $80.74(7.34)$ & $89.33(6.63)$ & 74.07 (10.14) & 76.25 (12.96) \\
\hline p-Value & 0.804 & 0.109 & 0.207 & 0.763 \\
\hline \multicolumn{5}{|l|}{ BMI } \\
\hline Less than 18.5 & $80.22(6.62)$ & $87.63(6.26)$ & $75.62(8.55)$ & $74.84(13.14)$ \\
\hline 18.5 to 24.9 & $80.37(6.50)$ & $87.80(7.09)$ & $75.07(8.30)$ & $75.86(11.24)$ \\
\hline 25.0 to 29.9 & $88.23(6.28)$ & $94.29(3.91)$ & $83.00(7.11)$ & $85.78(10.13)$ \\
\hline p-Value & $0.030 *$ & 0.104 & 0.116 & 0.142 \\
\hline \multicolumn{5}{|l|}{ Year of study } \\
\hline II & $80.68(3.46)$ & $85.37(5.99)$ & $78.81(4.60)$ & $75.87(11.62)$ \\
\hline III & $79.63(7.28)$ & $87.83(8.73)$ & $74.60(8.73)$ & $73.60(13.06)$ \\
\hline IV & $79.98(5.95)$ & $87.06(5.22)$ & $76.00(8.11)$ & $74.29(10.32)$ \\
\hline V & $80.16(7.02)$ & $87.74(7.09)$ & $74.26(8.90)$ & $76.23(11.51)$ \\
\hline Internship & $82.15(7.30)$ & $90.40(6.12)$ & $75.94(8.95)$ & $77.61(13.71)$ \\
\hline p-Value & 0.516 & 0.067 & 0.256 & 0.668 \\
\hline \multicolumn{5}{|l|}{ Monthly Stipend } \\
\hline Yes & $81.58(7.04)$ & $89.52(6.15)$ & $75.93(8.68)$ & 76.75 (12.67) \\
\hline No & $80.11(6.43)$ & $87.28(6.98)$ & $75.28(8.33)$ & 75.39 (11.69) \\
\hline p-Value & 0.168 & $0.040^{*}$ & 0.633 & 0.482 \\
\hline \multicolumn{5}{|c|}{ Alcohol Consumption } \\
\hline Consumers & $80.64(7.08)$ & $89.17(6.92)$ & $73.18(10.47)$ & $77.31(10.37)$ \\
\hline Non-consumers & $80.49(6.51)$ & $87.55(6.76)$ & $76.12(7.64)$ & $75.33(12.37)$ \\
\hline p-Value & 0.896 & 0.169 & 0.092 & 0.340 \\
\hline
\end{tabular}

PHY $=$ Physiological, $\quad$ PSY $=$ Psychological, SOCL $=$ Social. $*$ Significant at $\mathrm{p}<0.05, * *$ Significant at $\mathrm{p}<0.01$ 


\subsection{Socio-demographic Characteristics and SRH}

The overall SRH of students was significantly higher among those with BMI of 25.0 to $29.9(\mathrm{M}=88.23, \mathrm{SD}=6.28)$ as compared to those with BMI of less than $18.5(\mathrm{M}=80.22$, $\mathrm{SD}=6.62, p=0.027)$ and 18.5 to $24.9(\mathrm{M}=80.37, \mathrm{SD}=6.50$, $p=0.027)$. Males $(\mathrm{M}=88.96, \mathrm{SD}=6.80, p=0.001)$ self-rated physiological health score was significantly higher relative to that of females $(\mathrm{M}=85.41, \mathrm{SD}=6.23)$. In addition, students who had monthly stipend $(\mathrm{M}=89.52, \mathrm{SD}=6.15)$ perceived their health status to be better $(p=0.040)$ than those without $(\mathrm{M}=87.28, \mathrm{SD}=6.98)$ (Table 4).

\subsection{Socio-demographic Characteristics and HPL}

No significant difference in the overall mean HPL score was observed among the various categories of the demographic characteristics (Table 5). However, among the subscales of HPL, the score of physical activity was found to vary by gender and consumption of alcohol. Males $(\mathrm{M}=2.12$, $\mathrm{SD}=0.58, \quad p=0.005)$ and alcohol consumers $(\mathrm{M}=2.22$, $\mathrm{SD}=0.63, p=0.016$ ) were found to have significantly higher physical activity than their counter parts.

Table 5. Comparison of the scores of HPLP-II and its dimensions across categories of demographic characteristics.

\begin{tabular}{|c|c|c|c|c|c|c|c|}
\hline Characteristics & Overall HPLP-II, M (SD) & HR, M (SD) & SG, M (SD) & PA, M (SD) & $\mathbf{N}, \mathbf{M}$ (SD) & IR, M (SD) & SM, M (SD) \\
\hline \multicolumn{8}{|l|}{ Gender } \\
\hline Male & $2.48(0.30)$ & $2.11(0.48)$ & $3.19(0.39)$ & $2.12(0.58)$ & $2.00(0.41)$ & $2.88(0.48)$ & $2.57(0.45)$ \\
\hline Female & $2.48(0.31)$ & $2.12(0.51)$ & $3.28(0.39)$ & $1.87(0.48)$ & $2.04(0.41)$ & $2.99(0.50)$ & $2.48(0.48)$ \\
\hline$p$-Value & 0.880 & 0.847 & 0.171 & $0.005 * *$ & 0.539 & 0.122 & 0.209 \\
\hline \multicolumn{8}{|l|}{ Age } \\
\hline Less or equal 25 & $2.48(0.30)$ & $2.10(0.49)$ & $3.23(0.40)$ & $2.05(0.57)$ & $2.00(0.40)$ & $2.91(0.49)$ & $2.57(0.46)$ \\
\hline Greater than 25 & $2.48(0.31)$ & $2.16(0.49)$ & $3.17(0.38)$ & $2.03(0.55)$ & $2.04(0.43)$ & $2.95(0.50)$ & $2.48(0.45)$ \\
\hline \multicolumn{8}{|l|}{ BMI } \\
\hline Less than 18.5 & $2.46(0.31)$ & $2.12(0.51)$ & $3.22(0.40)$ & $1.99(0.64)$ & $1.94(0.41)$ & $2.91(0.53)$ & $2.53(0.46)$ \\
\hline 18.5 to 24.9 & $2.48(0.30)$ & $2.10(0.47)$ & $3.22(0.39)$ & $2.07(0.51)$ & $2.03(0.40)$ & $2.91(0.47)$ & $2.55(0.46)$ \\
\hline 25.0 to 29.9 & $2.67(0.32)$ & $2.42(0.64)$ & $3.22(0.30)$ & $2.13(0.78)$ & $2.40(0.35)$ & $3.04(0.43)$ & $2.78(0.29)$ \\
\hline$p$-Value & 0.305 & 0.340 & 0.999 & 0.638 & $0.028 *$ & 0.830 & 0.516 \\
\hline \multicolumn{8}{|l|}{ Year of study } \\
\hline II & $2.56(0.31)$ & $2.11(0.44)$ & $3.40(0.31)$ & $2.05(0.46)$ & $2.18(0.38)$ & $2.99(0.49)$ & $2.60(0.53)$ \\
\hline $\mathrm{V}$ & $2.45(0.30)$ & $2.10(0.50)$ & $3.16(0.40)$ & $2.11(0.57)$ & $1.92(0.39)$ & $2.88(0.44)$ & $2.49(0.45)$ \\
\hline Internship & $2.54(0.30)$ & $2.21(0.46)$ & $3.25(0.37)$ & $2.05(0.52)$ & $2.15(0.41)$ & $2.96(0.53)$ & $2.54(0.47)$ \\
\hline p-Value & 0.384 & 0.722 & 0.152 & 0.287 & $0.007 * *$ & 0.832 & 0.636 \\
\hline \multicolumn{8}{|l|}{ Monthly Stipend } \\
\hline Yes & $2.50(0.29)$ & $2.11(0.44)$ & $3.25(0.38)$ & $1.98(0.54)$ & $2.11(0.39)$ & $2.96(0.48)$ & $2.56(0.45)$ \\
\hline No & $2.47(0.31)$ & $2.11(0.51)$ & $3.20(0.40)$ & $2.07(0.57)$ & $1.97(0.41)$ & $2.89(0.49)$ & $2.54(0.46)$ \\
\hline$p$-Value & 0.507 & 0.984 & 0.427 & 0.310 & $0.029 *$ & 0.430 & 0.792 \\
\hline \multicolumn{8}{|l|}{ Alcohol Consumption } \\
\hline Consumers & $2.51(0.33)$ & $2.09(0.53)$ & $3.14(0.40)$ & $2.22(0.63)$ & $2.01(0.43)$ & $2.93(0.47)$ & $2.66(0.45)$ \\
\hline Non-consumers & $2.47(0.30)$ & $2.12(0.47)$ & $3.24(0.39)$ & $1.99(0.53)$ & $2.01(0.40)$ & $2.91(0.50)$ & $2.51(0.45)$ \\
\hline$p$-Value & 0.430 & 0.740 & 0.130 & $0.016^{*}$ & 0.872 & 0.813 & 0.057 \\
\hline
\end{tabular}

$\mathrm{HR}=$ Health Responsibility, IR=Interpersonal Relationship, $\mathrm{N}=$ Nutrition, $\mathrm{PA}=$ Physical Activity, SM=Stress Management, SG=Spiritual Growth, *Significant at $\mathrm{p}<0.05, * *$ Significant at $\mathrm{p}<0.01$

Using nutrition as the dependent variable, differences were observed in BMI, year of study and monthly stipend. Significantly higher $(p=0.040)$ score of nutrition was observed among students with BMI of 25.0 to 29.9 ( $\mathrm{M}=2.40$, $\mathrm{SD}=0.35)$ as compared to those with $<18.5 \mathrm{BMI}(\mathrm{M}=1.94$, $\mathrm{SD}=0.41$ ). Post hoc analysis revealed that only students at internship $(\mathrm{M}=2.15, \mathrm{SD}=0.41)$ had significantly higher nutrition score $(p=0.027)$ as compared to those in fifth year $(\mathrm{M}=1.92, \mathrm{SD}=0.39)$. Students with monthly stipend $(\mathrm{M}=2.11$, $\mathrm{SD}=0.39)$ had significantly higher $(p=0.029)$ nutrition score as compared to those without monthly stipend $(\mathrm{M}=1.97$, $\mathrm{SD}=0.41)$.

\subsection{Correlation of SRH and HPL with Their Dimensions}

The overall SRH score was significantly correlated with health responsibility $(\mathrm{r}=0.179, p=0.013)$, physical activity $(\mathrm{r}=0.247, p=0.001)$, spiritual growth $(\mathrm{r}=0.502, p<0.001)$, nutrition $(\mathrm{r}=0.170, p=0.019)$, interpersonal relationship $(\mathrm{r}=0.459, \quad p<0.001)$, and stress management $(\mathrm{r}=0.363$, $p<0.001)$ in addition to the overall HPL score $(\mathrm{r}=0.493$, $p<0.001)$. On the other hand, overall HPL score was significantly correlated with physiological ( $\mathrm{r}=0.239$, $p<0.001)$, psychological $(\mathrm{r}=0.424, p<0.001)$, and social health $(\mathrm{r}=0.452, p<0.001)$ (Table 6).

\subsection{Association of SRH and HPL}

Significant association between SRH and HPL was observed $(p=0.033)$. Students who had good and excellent HPL had self-rated themselves as almost 5 times $(\mathrm{AOR}=4.97$, 95\% CI: $1.28,19.32$ ), and were 3.73 times (AOR $=3.73,95 \%$ CI: $1.09,12.80)$ more healthy than those who had poor HPL, respectively. Moreover, SRH was significantly associated 
with physical activity $(p=0.042)$ and interpersonal relationship $(p=0.021)$. Students who had excellent physical activity of HPL self-rated themselves as 17.24 times healthier than those who had poor HPL. Moreover, interpersonal relationship of HPL was higher in those students who had good $(\mathrm{AOR}=17.84,95 \% \mathrm{CI}: 2.10,151.95)$, and excellent (AOR=3.36, 95\% CI: 1.02, 11.02) HPL compared to students who had poor HPL (Table 7).

Table 6. Correlation matrix of SHMS V1.0 and HPLP-II along with their dimensions.

\begin{tabular}{|c|c|c|c|c|}
\hline & Physiological & Psychological & Social Health & Overall SRH \\
\hline HPLP Dimensions & $\mathbf{r}$ (p-value) & r (p-value) & r (p-value) & r (p-value) \\
\hline Health Responsibility & $0.049(0.501)$ & $0.182(0.011)$ & $0.170(0.018)$ & $0.179(0.013)$ \\
\hline Physical Activity & $0.105(0.146)$ & $0.225(0.002)$ & $0.227(0.002)$ & $0.247(0.001)$ \\
\hline Nutrition & $0.136(0.060)$ & $0.158(0.029)$ & $0.097(0.181)$ & $0.170(0.019)$ \\
\hline Interpersonal relationship & $0.149(0.039)$ & $0.333(<0.001)$ & $0.622(<0.001)$ & $0.459(<0.001)$ \\
\hline Stress Management & $0.282(<0.001)$ & $0.288(<0.001)$ & $0.263(<0.001)$ & $0.363(<0.001)$ \\
\hline
\end{tabular}

Table 7. Association of SHMS V1.0 and HPLP-II and its dimensions.

\begin{tabular}{|c|c|c|c|}
\hline Dimensions & AOR & $95 \% \mathrm{CI}$ & $p$-value \\
\hline HPLP & & & 0.033 \\
\hline Poor & Ref. & - & \\
\hline Moderate & 3.15 & $0.89,11.10$ & 0.074 \\
\hline Good & 4.97 & $1.28,19.32$ & 0.021 \\
\hline Excellent & 3.73 & $1.09,12.80$ & 0.037 \\
\hline Health Responsibility & & & 0.191 \\
\hline Poor & Ref. & - & \\
\hline Moderate & 0.62 & $0.20,1.89$ & 0.397 \\
\hline Good & 2.45 & $0.59,10.06$ & 0.215 \\
\hline Excellent & 1.91 & $0.57,6.41$ & 0.297 \\
\hline Physical Activity & & & 0.042 \\
\hline Poor & Ref. & - & \\
\hline Moderate & 1.78 & $0.56,5.66$ & 0.331 \\
\hline Good & 2.7 & $0.84,8.65$ & 0.095 \\
\hline Excellent & 17.24 & $2.02,147.01$ & 0.009 \\
\hline Spiritual Growth & & & 0.437 \\
\hline Poor & Ref. & - & \\
\hline Moderate & 1.76 & $0.42,7.44$ & 0.443 \\
\hline Good & 1.09 & $0.37,3.24$ & 0.879 \\
\hline Excellent & 2.64 & $0.74,9.46$ & 0.136 \\
\hline Nutrition & & & 0.337 \\
\hline Poor & Ref. & - & \\
\hline Moderate & 1.39 & $0.46,4.18$ & 0.557 \\
\hline Good & 6.81 & $0.80,57.99$ & 0.079 \\
\hline Excellent & 1.02 & $0.33,3.13$ & 0.976 \\
\hline Interpersonal relationship & & & 0.021 \\
\hline Poor & Ref. & - & \\
\hline Moderate & 2.47 & $0.80,7.60$ & 0.116 \\
\hline Good & 17.84 & $2.10,151.95$ & 0.008 \\
\hline Excellent & 3.36 & $1.02,11.02$ & 0.046 \\
\hline Stress Management & & & 0.056 \\
\hline Poor & Ref. & - & \\
\hline Moderate & 0.4 & $0.14,1.14$ & 0.085 \\
\hline Good & 2.01 & $0.49,8.28$ & 0.332 \\
\hline Excellent & 1.71 & $0.41,7.18$ & 0.465 \\
\hline
\end{tabular}

BMI, Age, Sex, Study year, Alcohol consumption, Monthly stipend were controlled in the analysis

\section{Discussion}

Our study revealed that the majority $(80.5 \%)$ of the medical students assessed their SRH as healthy. The current study showed that the medical students were better in their SRH, this may be attributable to health awareness and knowledge in addition to their fledgling age. This finding is similar to a previous study conducted in Turkey, where $80.5 \%$ of the students self-rated themselves as healthy [9]. Moreover, physiological health status was relatively higher compared to psychological and social health status. This finding is consistent with a study done in china, where international students had significantly higher scores compared to their Chinese counterparts in the physiological health status [6].

It was noticed that the overall SRH was substantially related to BMI (25.0 to 29.9). This finding showed that medical students with higher BMI had a higher SRH. In contrast to the current study, the China study also reported that medical students with low BMI perceived their SRH better than those with high BMI [6]. The score of physiological subscale was significantly related to gender and monthly stipend. Males self-perceived physiological health score was significantly higher relative to that of their female counterparts. Males may have relatively more free time for physical activity, as a consequence, they may appear to be physiologically healthier than their female counterparts.

The distinction between male and female physiological health could be explained by the biological and sociocultural environment inequalities [11]. Males and females seem to experience their free time differently. Female's free time is often interrupted - routine chores in the house (greater amount of housework, chatting with friends, watching movies and reading books, going to the market among others); which may make it hard for them to relax. This finding is consistent to the studies done in India, Brazil, Sweden [5, 7, 12], but inconsistent to the study done in Iran [8]. On the other hand, as a culture in Eritrea, males are not forced by their parents to do any house related work. Thus, after class they do have more free time for playing football, walking, and cycling. Altogether, females generally have limited opportunities when compared with males to engage in physical activity, both inside and outside school due to cultural reasons.

Furthermore, students with monthly stipend had a higher physiological health score compared to those without. We believe that money buys goods and services that improve health or it may incentivize indulgence in behaviors that can undermine health. Students with no incomes typically have no money to spend taking care of themselves, whether paying for medicine, or healthy food. This finding is congruent with a study done in Turkey which indicated that individuals in 
better economic situation were more likely to rate their physiological health as good [9].

The overall mean score of HPL among medical students was moderate. Indeed, HPL among medical students was not satisfactory, since the mean scores of health responsibility, physical activity and nutrition were interestingly low. College students are relatively young and may not worry about their health, may not be engaged in habitual physical activity, and more likely to skip breakfast, to stay up late at night, and to eat irregularly. This finding is in agreement with the studies done in Japan and Turkey [4, 9]. However, the mean scores of spiritual growth, interpersonal relationship and stress management were relatively higher compared to other dimensions, which is consistent with the findings from the studies in Japan and Turkey [4, 9].

Based on our study, no significant difference in the overall mean score of HPL was observed among the various categories of the demographic characteristics. However, among the subscales of HPL, there was a statistically significant relationship between some demographic variables and the scores of physical activity and nutrition. Physical activity as a dependent variable was found to vary by gender and consumption of alcohol. Although the overall mean score of physical activity was low, males reported higher physical activity compared to females.

On the other hand, significant difference in physical activity was observed among alcohol consumers and nonconsumers. In line with our research, a study done in United States (US) revealed that alcohol consumption is positively related with total minutes of any physical activity. Ten extra drinks per month are associated with an average of 2.2 more minutes per week of total physical activity. When compared to current shunners, light, moderate, and heavy drinkers exercise approximately 5.7, 10.1, and 19.9 minutes more per week [17].

Using nutrition as the dependent variable, differences were observed in BMI, year of study and monthly stipend. The highest nutrition scores were observed among students with BMI (25.0 to 29.9), internship students and students with monthly stipend. Several studies have revealed that the students with higher income levels had increased dietary intake, which may promote the risk of gaining weight and high risk of suboptimal health [6].

Internship students have relatively less academic load/less pressure to maintain a healthy diet as compared to others. Usually in the first years the classes are packed with 22 credit hours per semester. Because of this reason and others like new environment, new friendship, financial pressure, starting of responsibility in their lives among others; students tend to have stress which might negatively affect their eating habit, physical activity, social activities, and sleeping pattern as compared to those who are in their last year academic level. This finding is in agreement with the study done in China which indicated that students with higher levels of education are less likely to engage in risky behaviors such as unhealthy diet, and more likely to have healthy behaviors related to diet and exercise [6].
The overall SRH score was significantly correlated with health responsibility, physical activity, spiritual growth, nutrition, interpersonal relationship, and stress management in addition to the overall HPL score. On the other hand, overall HPL score was significantly correlated with physiological, psychological, and social health. Our study showed that the SRH is positively correlated with HPL. However, poor lifestyle is a risk factor for SHS, and adopting a healthier lifestyle can improve SHS [3]. In this respect, our finding is comparable with a study done in China [6].

Significant association between SRH and HPL was observed. The odds of healthy self-rating was almost five and four times more among students with good and excellent HPL, respectively, compared to those who had poor HPL. This indicates that HPL was better linked with SRH. Moreover, SRH was significantly associated with physical activity and interpersonal relationship. High scores on physical activity and interpersonal relations indicated that the students had self-rated themselves healthier than those who had poor HPL. This finding is consistent with previous studies done in china $[6,18]$.

This study has some limitations. All the information was obtained from self-reported questionnaires, which could result in potential information and recall bias. Above all, this was a cross-sectional design, which did not allow us to assess causality or the directionality of relationships. Moreover, the SRH and HPL were assessed by questionnaires, these measures are not equivalent to clinical diagnosis, and thus future studies with diagnostic interviews should be used.

\section{Conclusions}

Generally, these findings provide evidence supporting the influence of socio-cultural factors on SRH and HPL. Based on our study, gender, BMI and monthly stipend play a major role in the SRH of the students whereas gender, alcohol consumption, BMI, study year and monthly stipend play a major role in the HPL. Moreover, our findings showed that SRH is positively correlated with HPL. Poor lifestyle is a risk factor for SHS. Conversely, adopting a healthier lifestyle can improve SHS. Hence, by adopting a healthier lifestyle, health status of an individual can be significantly improved. To the best of our knowledge, this is the first study reporting on the influence of socio-cultural factors on medical college students' SRH and HPL in Eritrea. Therefore, the findings of this study will provide significant information to the medical college, and will help students to adopt and establish a healthy lifestyle.

\section{Abbreviations}

ANOVA: Analysis Of Variance; AOR: Adjusted Odds Ratio; BMI: Body Mass Index; HIC: High-Income Countries; HPL: Health-Promoting Lifestyles; HPLP-II: HealthPromoting Lifestyle Profile-II; IQR: Interquartile range; LMIC; Low-and Medium-Income Countries; OSM: Orotta School of Medicine; SHMS-V1: Sub-Optimal Health 
Measurement Scale Version-1; SHS: Sub-Optimal Health Status; SRH: Self-Rated Health status; SSA: Sub Saharan Africa; WHO: World Health Organization.

\section{Data Availability}

All the results of this research were based on the use of primary data, however, the complete dataset used and analyzed at the present study are not available in public due to the requirement of confidentiality. The electronic and paper form dataset are available with the corresponding author and can be accessed upon a reasonable request.

\section{Ethical Approval}

Ethical approval was obtained from National Commission for Higher Education ethics committee with a ref. No.: BHEA143/710/18. The participants' rights were protected by ensuring voluntary participation and supported by written consent; after explaining the purpose, nature, time to conduct the study, the potential benefits and risks of the study and data collection techniques. The anonymity and confidentiality of the participants were assured and treated as strictly confidential. Furthermore, the participants' were not required to mention their names and they were given a full right to drop from participating in the study.

\section{Consent}

This manuscript has not been published in another place and is not under consideration by another journal. All authors have approved the final manuscript and agreed for its publication.

\section{Conflicts of Interest}

The authors declare that they have no conflicts of interest regarding the publication of this article.

\section{Funding Statement}

There was no funding available for this research.

\section{Authors' Contributions}

IAA, ZAD and DYC conceived, designed, managed the data collection, and critically reviewed the manuscript. GGB, OOA and YFB were involved in paper drafting and critical revision of the manuscript for important intellectual content. EHT was involved in analysis, interpretation of data and drafting of the manuscript. All authors read and approved the final manuscript.

\section{Acknowledgements}

We are deeply indebted to express our sincere gratitude to the National Commission for Higher Education, Eritrea and
Orotta School of Medicine for their permission and cooperation which allowed us to conduct our research with great ease. Our gratitude also goes to respective school managers and staffs who devoted their time in facilitating the data collection process. At last, we equally thank the cooperation of the medical students for their participation. The manuscript has been submitted as preprint in Research Square with DOI: 10.21203/rs.3.rs-15692/v1.

\section{References}

[1] Esmaeili A, Salem Z, MSF, Rezaeian M, Nejad E., "Assessment of health-promoting lifestyle in medical students of Rafsanjan university of medical sciences, Iran, in 2014," JOHE, vol. 4, no. 1, pp. 19-25, 2015.

[2] Ma C, Xu W, Zhou L, Ma S, Wang Y., "Association between lifestyle factors and suboptimal health status among Chinese college freshmen: a cross-sectional study," BMC Public Health, vol. 18, no. 105, pp. 1-9, 2018.

[3] Jianlu B, Ying H, Ya X, et al., "Association of lifestyle factors and suboptimal health status: a cross-sectional study of Chinese students," BMJ Open, vol. 4, no. 6, pp. 1-7, 2014.

[4] Koichi CW \& Kimiyo H., "Assessment of health-promoting lifestyle profile in Japanese university students," Env. Heal. Prev Med., vol. 17, no. 2012, pp. 222-227, 2012.

[5] Chouhan S., "Analysing health promoting life styles of medical students in Bhopal, Madhya Pradesh, India by HPLPII," Int. J. Community Med. Public Heal., vol. 4, no. 1, pp. 195-199, 2017.

[6] Lolokote S, Hidru TH, Li X., "Do socio-cultural factors influence college students' self rated health status and healthpromoting lifestyles? A cross-sectional multicenter study in Dalian, China," BMC Public Health, vol. 17, no. 1, pp. 1-14, 2017.

[7] Pacheco RL, Santos-silva DA, Gordia AP, Petroski EL., "Sociodemographic determinants of university students' lifestyles," Rev. salud pública, vol. 16, no. 3, pp. 382-393, 2014.

[8] Moghaddam F, Norouzi S, Norouzi M, Norouzi A, Neisary Z., "Evaluation of lifestyle health promotion of dormitory medical students regarding comprehensive aspects," Crescent J. Med. Biol. Sci., vol. 4, no. 4, pp. 205-210, 2017.

[9] Nacar M, et al., "Health promoting lifestyle behaviour in medical students: a multicentre study from Turkey," Asian Pac J Cancer Prev., vol. 15, no. 20, pp. 8969-8974, 2014.

[10] Wu S, Wang R, Zhao Y, et al., "The relationship between self-rated health and objective health status: a populationbased study," BMC Public Health, vol. 13, no. 320, pp. 1-9, 2013.

[11] Zarini GG, Vaccaro JA, Terris MAC, et al., "Lifestyle behaviors and self-rated health: the living for health program," J. Environ. Public Health, vol. 2014, no. 315042, pp. 1-9, 2014.

[12] Schmidt M., "Predictors of self-rated health and lifestyle behaviours in Swedish university students," Glob. J. Health Sci., vol. 4, no. 4, pp. 1-14, 2012. 
[13] Ay S, Yanikkerem E, Çalım Sİ, Yazıcı M., "Health-promoting lifestyle behaviour for cancer prevention: a survey of Turkish university students," Asian Pacific J Cancer Prev., vol. 13, no. 5, pp. 2269-2277, 2012.

[14] Wang D, Ou C, Chen M, Duan N., "Health-promoting lifestyles of university students in mainland China," $B M C$ Public Health, vol. 9, no. 379, pp. 1-9, 2009.

[15] Saleh Al-Hemyari S, \& Abdulrahaman A., "Assessment of suboptimal health status and their associated risks in university students: a cross-sectional study, UAE," J. Pharm. Res., vol. 11, no. 8, pp. 932-936, 2017.
[16] Riemenschneider H, Balazs P, Balogh E, et al., "Do sociocultural factors influence medical students ' health status and health- promoting behaviors? A cross-sectional multicenter study in Germany and Hungary," BMC Public Health, vol. 16, no. 576, pp. 1-10, 2016.

[17] Maclean JC., "Do alcohol consumers exercise more? Findings from a national survey," Am J Heal. Promot., vol. 24, no. 1, pp. 2-10, 2009.

[18] Chen J, Xiang H, Jiang P, et al., "The role of healthy lifestyle in the implementation of regressing suboptimal health status among college students in China: a nested case-control study," Int. J. Environ. Res. Public Heal., vol. 14, no. 240, pp. 1-17, 2017. 